\title{
STIMULI-SENSITIVE HYDROGELS FOR PHARMACEUTICAL AND MEDICAL APPLICATIONS ${ }^{\dagger}$
}

\author{
UDC 544.773.432
}

\section{Snežana Ilić-Stojanović ${ }^{*}$, Ljubiša Nikolić ${ }^{1}$, Vesna Nikolić ${ }^{1}$, Slobodan Petrović ${ }^{2}$, Mihajlo Stanković ${ }^{1}$, Ivana Mladenović-Ranisavljević ${ }^{1}$}

${ }^{1}$ University of Niš, Faculty of Technology, Bulevar oslobođenja 124, Leskovac, Serbia ${ }^{2}$ University of Belgrade, Faculty of Technology and Metallurgy, Karnegijeva 4, Belgrade, Serbia

\begin{abstract}
Hydrogels are three-dimensional cross-linked hydrophilic polymers that swell in water and aqueous solutions without dissolving in them. They are very sensitive to environmental stimulus, which is manifested by a sharp phase transition. This feature is important for their application in the pharmaceutical field, especially for making formulations with controlled release of active ingredients, with the correction of the solubility, degradation and their toxicity reducing. Because of the compatibility with living tissues, hydrogels can be used in different medical purposes (for making contact lenses, stents, balloon catheters, artificial muscles, substitutes for arteries and veins, trachea, oviduct). This work presents methods (chemical and physical) for obtaining hydrogels, their properties and sensitivity to environmental stimuli (temperature, $p H$, magnetic field), as well as their potential application in medicine and pharmacy.
\end{abstract}

Key words: hydrogels, intelligent gels, drug delivery systems, cross-linking, $\mathrm{N}$-isopropylacrilamide

\section{INTRODUCTION}

Hydrogel is described as smart or intelligent gel when its sol-gel transition occurs at conditions that can be induced in a living body. Hydrogels are formed when a threedimensional polymeric network is loosely cross-linked. They swell in water but do not dissolve in it. The water holding capacity of the hydrogels arise mainly due to the presence of hydrophilic groups, amino, carboxyl and hydroxyl groups, in the polymer chains. According to Hoffman, the amount of water present in a hydrogel may vary from $10 \%$ to thousands of times of the weight of the xerogel [1-3]. A xerogel may be defined as a polymeric network devoid of water. The water holding capacity of a xerogel is

Received April 13 ${ }^{\text {th }}, 2011$; revised May 31 $1^{\text {st }}$, 2011; accepted June $1^{\text {st }}, 2011$.

${ }^{\dagger}$ Acknowledgement: The paper is a part of the research done within the project TR 34012. The authors would like to thank to the Ministry of Education and Science, Republic of Serbia.

*Corresponding author: E-mail: ilic.s.snezana@gmail.com. 
dependent on the number of the hydrophilic groups and crosslinking density. With higher number of the hydrophilic groups, higher is the water holding capacity while with an increase in the crosslinking density there is a decrease in the equilibrium swelling due to the decrease in the hydrophilic groups. Hydrogels may display reversible sol-gel transitions, induced by changes in the environmental conditions like temperature, $\mathrm{pH}$, ionic strength, phase separation, wave length of light, glucose, crystallinity, pressure, magnetic field, ultrasound, etc. (Figure 1). Their classification may be based on the source: natural or synthetic gels; on the nature of cross-linking: covalent and physical gels; on the nature of the network: homopolymer, copolymer, interpenetrating or double networks; on the presence of pores: homogeneous (optically transparent), microporous and macroporous hydrogels; on their fate in an organism: degradable and non-degradable hydrogels $[1,4,5]$.

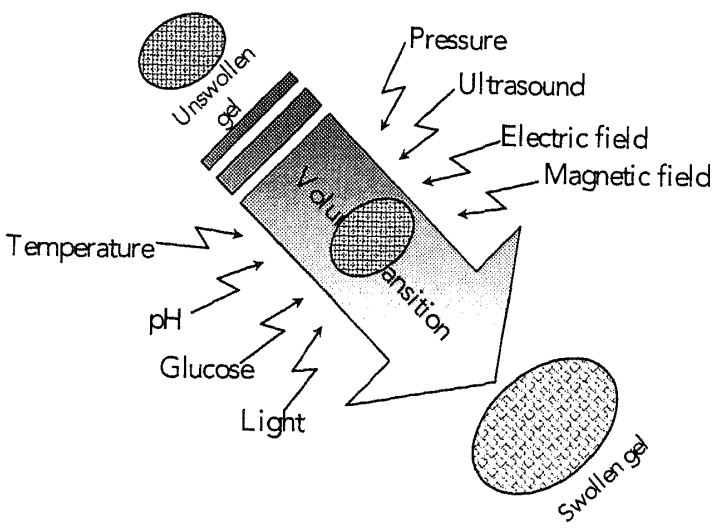

Fig. 1. Stimuli-sensitive hydrogels [5]

Interest in polymer hydrogels began in the 1950s, after the submitted report for the phase transition of $\mathrm{pH}$-sensitive polymers [6]. During the last few decades, the number of papers published on this subject increased exponentially and continued to increase linearly during the last few years. Poly( $N$-isopropylacrylamide) (pNIPAM) is a typical temperaturesensitive polymer which owns hydrophilic and hydrophobic groups (Figure 2).<smiles>C=CC(=O)NC(C)C</smiles>

Fig. 2. Structural formula of NIPAM

Coover and Shearer [7] have synthesized first $N$-isopropylacrylamide (NIPAM) in 1953. Heskins and Guillet [8] surveyed effects of external stimuli to certain polymers in the 1960s. They found that lower critical solution temperature (LCST) of poly- $N$ isopropylacrylamide is $32{ }^{\circ} \mathrm{C}$, under standard conditions where it passes through the phase transition from hydrophilic to hydrophobic state. 
In the early 1950s Wichterle and Lìm proposed a new biomaterials design for applications in ophthalmology. The main features of the design were: (a) shape stability and softness similar to that of the soft surrounding tissue; (b) chemical and biochemical stability; (c) absence of extractables; and (d) high permeability for water-soluble nutrients and metabolites. Based on this rationale, in 1953 they synthesized the first hydrogels by copolymerization of 2-hydroxyethyl-methacrylate with ethylene dimethacrylate [9]. They also invented a new process for preparing a sparingly cross-linked polymeric hydrogel structure based on polyethylene glycol methacrylate and acrylamide [10]. Wichterle prepared the first soft (hydrogel-based) contact lenses by the spin casting process [11]. The first studies on the biocompatibility of hydrogels were published in 1959. In the following period, soft contact lens with thin edge (Figure 3) have been developed [12-16].

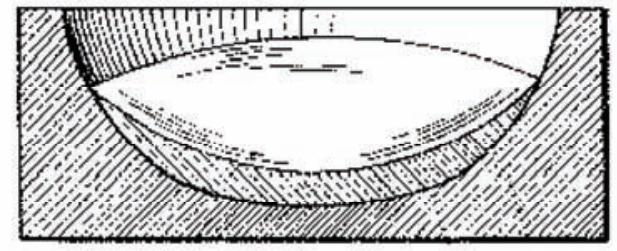

Fig. 3. Soft contact lens with thin edge [14]

Traditional medicines, devoted to the achievement of systemic levels sufficient to reach the target by an immediate or progressive drug-flooding of the body, are no longer valid for most of the emergent synthetic and biotechnological therapeutic molecules, owing to the instability and toxicity problems or to hindrances to reach the target structure from the systemic circulation [17]. For the development of modern health care products, there has been an increased interest for hydrogels, which can be added to their easy availability and desirable properties.

\section{PREPARATION OF HydRogels}

By definition, hydrogels are crosslinked polymer networks with hydrophilic properties. They are generally prepared based on hydrophilic monomers, but hydrophobic monomers are sometimes used in hydrogels preparation in order to regulate the properties for specific applications [18]. In general, the three integral parts of the hydrogels synthesis are monomer, initiator, and crosslinker. To control the heat of polymerization and the final hydrogels properties, diluents as water or other aqueous solutions can be used. After the synthesis, the hydrogels mass needs to be washed to remove impurities left from the synthesis process. These include non-reacted monomers, initiators, crosslinkers, as well as unwanted products produced via side reactions (Figure 4). The hydrogels properties can be modulated by varying the synthetic factors, such as reaction vessel, time, temperature, monomer type, type of crosslinker, crosslinker-to-monomer ratio, monomer concentration, and type and amount of initiator. 


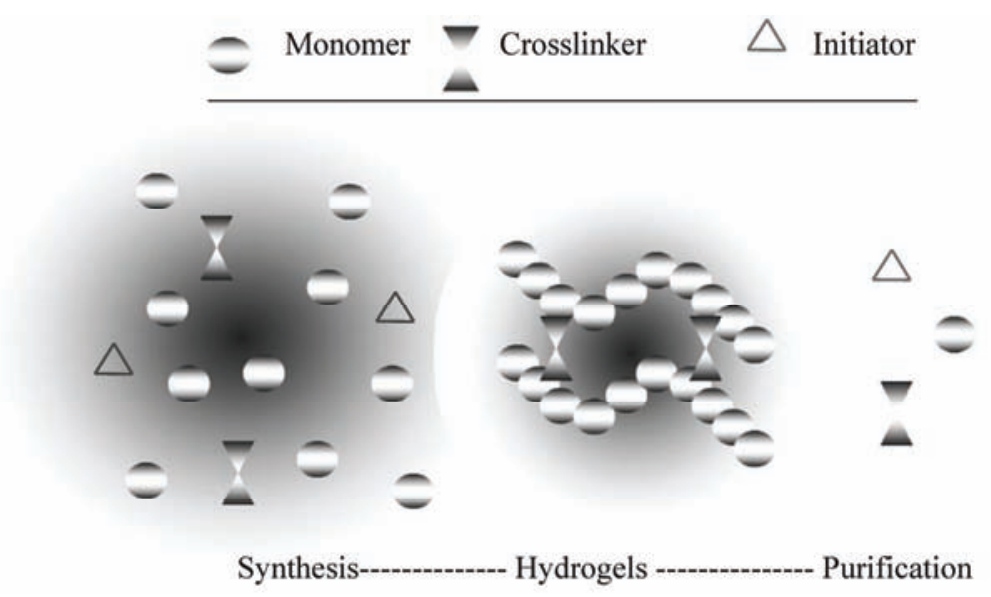

Fig. 4. Hydrogel synthesis [18]

From a physical point of view, the association of polymer-polymer, polymer-drug, or polymer-bioactive components can be established by means of: electrostatic interactions, hydrogen bonding, donor-acceptor, van der Waals forces, or even metal-ion coordination. There are clear examples of supramolecular systems in the living tissues constituted by this mechanism and even it is the basis for metabolic functions, cell growth and proliferation, or the pharmacological action of a great number of drugs. The chemical approach gives excellent opportunities for the design and development of bioactive polymer systems and polymer drugs, with a lot of possibilities for the modulation and control of the targeting of these very interesting bioactive systems.

Reversible chemical reactions of functional groups present in monomeric components, building blocks in polymer chains, linear polymerization with control of the molecular weight and molecular weight distribution, and crosslinking, are some of the possibilities of this very wide and attractive approach for the development of bioactive macromolecules of very high interest in "polymer therapeutics." The reversible chemical reactions are very frequent in nature and a single example is the reversible crosslinking of proteins based on disulfure links from aminoacid components of the macromolecular chains. Solid-liquid behaviors of hydrosol and hydrogel polymers, as well as approaches to convert a hydrosol to a hydrogels, are shown in Figure 5.

\subsection{Chemically cross-linked hydrogels}

Traditional methods for the synthesis of covalently cross-linked hydrogels include cross-linking copolymerization, cross-linking of reactive polymer precursors, and crosslinking via polymer-polymer reactions. Various approaches to the preparation of chemically cross-linked hydrogels have been described in the literature. 


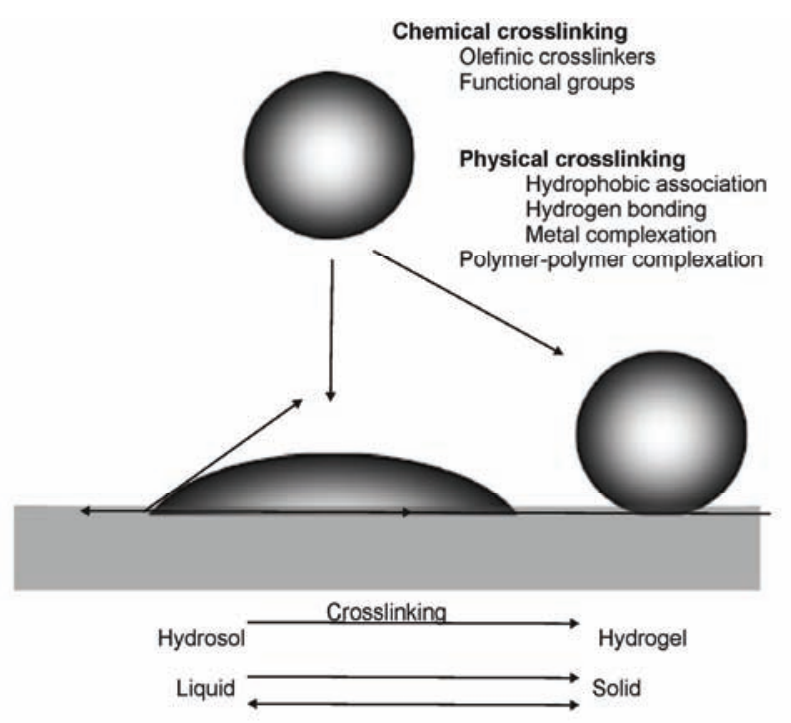

Fig. 5. Chemical and physical gels [18]

They include: (1) moderate irradiation of the concentrated aqueous solutions of two or more polymers or copolymers, in which part of their segments is endowed with hydrophilic groups; (2) polymerization by irradiation of aqueous solutions of two or more monomers or polymers in the presence of monomers; (3) chemically induced polymerization and cross-linking in an aqueous solution of monomers and cross-linking monomers equipped with appropriate functional group(s); (4) cross-linking due to chemical interactions between functional groups of a polymer and a macromer; (5) irradiation of a polymeric matrix penetrated by another monomer or polymer [1].

The following examples below, describing the preparation of hydrogels, illustrate the variety of inventive approaches for their preparation. To obtain the thermoreversibly hydrophilic and hydrophobic compound, NIPAM was dissolved in ethyl acetate and radicalpolymerized at $20-30{ }^{\circ} \mathrm{C}$ in the presence of the vinyl compound, and polymerization initiator azobisisobutylnitrile [19]. According to the invention JP 2000/264864, NIPAM is obtained by reaction between acrylonitrile and isopropyl alcohol in the presence of zeolite [20]. NIPAM was dissolved in a benzene solvent and radical-polymerized at $20-30{ }^{\circ} \mathrm{C}$ in the presence of the vinyl compound and initiator azobisisobutyronitrile to give the polymer which is pNIPAM having an intrinsic viscosity [21]. Controlled polymerization of NIPAM was achieved by atom transfer radical polymerization using ethyl 2-chloropropionate as initiator and $\mathrm{CuCl} /$ tris(2-dimethylaminoethyl)-amine as a catalytic system [22]. A process for preparing temperature-sensitive porous aquagel of pNIPAM includes such steps as dissolving NIPAM monomer and cross-linking agent in deionized water [23]. Hydrogels with crystalline colloidal array of water voids for macromolecule separations and detection are prepared by forming a medium porous around solid particles, with size selected for the voids (larger than the pores), then removing the particles without disrupting the hydrogel structure [24]. The invention CN 101704925 relates to a preparation method of the NIPAM-methacrylic acid/zirconium dioxide compound microgel, 
which is temperature- and pH-sensitive, has special absorption to proteins, and can be used for separating proteins [25]. Fast responsive and $\mathrm{pH}$-thermo-responsive copolymer hydrogels were prepared by $\gamma$-ray irradiation of mixed solutions of NIPAM and acrylic acid [26]. Also, a copolymer hydrogel of NIPAM and 2-hydroxypropyl methacrylate (HPMet) was synthesized by free radical polymerization [27] or by gamma irradiation [28]. Zhao et al. [29] presented a method of microwave irradiation synthesis, proposed for the preparation of thermo-sensitive pNIPAM hydrogels, which has much higher swelling ratio at $10{ }^{\circ} \mathrm{C}$ below the LCST, and much lower swelling ratio at $60{ }^{\circ} \mathrm{C}$ above the LCST, comparing to the hydrogels synthesized by water-bath method [29]. Preferred embodiment stimuli-responsive low solubility copolymer hydrogel compositions of the invention US 2010/203141 include polymerised NIPAM and water insoluble monomer or oligomer repeating units [30]. The polymer-based microbeads are manufactured from aqueous solution containing NIPAM and aqueous PAA or poly (methacrylic acid), mixed with N,N'-methylene bisacrylamide. Sodium dodecylbenzenesulfonate and ammonium persulfate were synthesized to give a micelle solution, which was dialyzed to give polymer microbead solution [31]. An intelligent gel is prepared from 2-acrylamide-2-methyl propanesulfonic acid and NIPAM through proportional mixing, adding the mixture to the aqueous solution of N,N'-methylenediacrylamide and polymerizing as it is shown in CN 1869087 [32]. Finally, a photoresponsive hydrogel is prepared by radical copolymerization of NIPAM, a vinyl monomer having a spirobenzopyran residue and crosslinker [33].

\subsection{Physically cross-linked hydrogels}

Physically, cross-linked hydrogels are formed spontaneously under appropriate conditions, without external cross-linking agents that are usually non-degradable. Their amorphous hydrophilic phase is held together because of the highly ordered aggregated chain segments and secondary molecular forces, such as hydrogel bonding, "Van der Waals" forces, or hydrophobic interactions. Some of the examples were given by Zhao et al. [34] where the $\mathrm{pH}$ sensitive, physically cross-linked polyampholyte gels were prepared. Also, polyurethane-b-PAAm hydrogels were prepared by Patel and Mequanint [35]. Mequanint et al. [36] synthesized physically cross-linked block copolymer hydrogels by controlled radical polymerization of polyurethane (PU) macroiniferter, coupled with (2,2-dimethyl-1,3-dioxolane) methyl methacrylate (DMDOMA), followed by selective hydrolysis of the DMDOMA into poly-(glycerol methacrylate) (PGMA). The resulting PU-b-PGMA hydrogels show reasonably high modulus of elasticity and their respective equilibrium water swelling could reach the $40 \%$ level, depending on the degree of hydrolysis of the DMDOMA block. Reversibly physical cross-linked copolymers, consisting of styrene, 2-hydroxyethyl methacrylate (HEMA) and NIPAM were presented in patent application WO 2000/046262 [37].

\section{STIMULI-SENSITIVE HYDROGELS}

Stimuli-sensitive hydrogels have ability to swell and de-swell according to conditions, which makes them interesting for use as new intelligent materials. Applications for biomedical fields have three functions: (a) sensing an external signal (sensor function), (b) evaluation (processor function) and (c) action (actuator function) which were developed as "intelligent gels" or "smart gels". The functions of stimuli-responsive gels can be 
roughly classified into three categories; (a) mechanical motion, (b) mass transport, and (c) conversion and transmission of information [18]. They can be used in controlled drug delivery to achieve: (1) constant concentration of therapeutically active compounds in the blood with minimum fluctuations; (2) predictable and reproducible release rates over a long period of time; (3) protection of bioactive compounds considering their very short half-life; (4) elimination of side-effects, waste of drug and frequent dosing; (5) optimized therapy and better patient compliance; (6) solution of the drug stability problem [38]. The following section describes $\mathrm{pH}$, temperature, and some of the biochemical analytes as representative stimuli modulating volume transitions in smart polymeric gels.

\subsection{Temperature-sensitive hydrogels}

Temperature-sensitive hydrogels are probably the most studied class of stimuli sensitive polymer in drug delivery research. These hydrogels are able to swell or de-swell as a result of change in the temperature of the surrounding fluid. They are classified into negatively thermosensitive, positively thermosensitive and thermally reversible gels. Hydrogels containing polymers, such as pNIPAM, methyl cellulose, pluronics, tetronics, and $\mathrm{N}$-vinyl caprolactam, are characterized by the temperature dependent sol-gel transition Tgel, which corresponds to the lower critical solution temperature (LCST), and by the gel-sol transition temperature, Tp - upper critical solution temperature (UCST) which corresponds to dissipation or precipitation of a gel [39].

Negative temperature-sensitive hydrogels have a lower critical solution temperature (LCST), which may be defined as the critical temperature below which the polymer swells in the solution while above it the polymer contracts. Below the LCST, the enthalpy term, related to the hydrogen bonding between the polymer and the water molecules, is responsible for the polymer swelling. When the temperature is raised above the LCST, the entropy term (hydrophobic interactions) dominates, leading to polymer contraction. The efficiency of the hydrogen bonding process has negative temperature dependence; above the LCST, the hydrogen bonds between the monomer side groups and water molecules, which would be increasingly disrupted with increasing temperature [40]. The backbones of the polymer, the long chains of $\mathrm{C}-\mathrm{C}$ bonds to which the side chains are attached are hydrophobic and tend to reduce their surface area exposed to the highly polar water molecules. They can do so by forming aggregates as shown in Figure 6. When hydrogen bonds between the side groups and the water are present, the aggregation of the backbone is prevented because the hydrogen bond interactions with the water molecules are stronger than the backbone interactions. When the hydrogen bonds are broken by increasing thermal agitation, aggregation takes place, resulting in shrinkage of the thermosensitive hydrogel with increasing temperature [41].

A positive temperature-sensitive hydrogel has an upper critical solution temperature (UCST). The hydrogel contracts upon cooling below the UCST. Polymer networks of poly(acrylic acid) (PAA) and polyacrylamide (PAAm) or poly(acrylamide-co-butylmethacrylate) exhibit positive temperature dependence of swelling [42]. Properties of thermoresponsive PNIPA hydrogels, P(NIPAM-co-AAm) and poly(NIPAM-co-N-hydroxymethylacrylamide-co-hydroxyethyl methacrylate) prepared by redox polymerization were investigated [43, 44]. Also, the behavior of water pNIPAM, poly(NIPAM-co-2-hydroxyethyl methacrylate), p(NIPAM-co-AAm) and poly(NIPAM-co-N,N-dimethylacrylamide) hydrogels, synthesized by radical polymerization were studied at large $[45,46]$. 


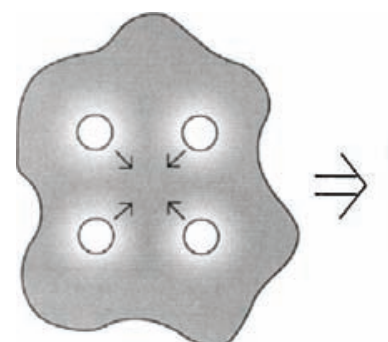

(a)

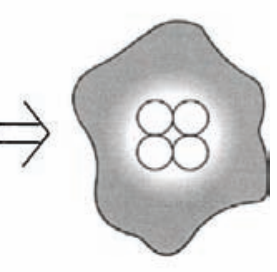

(b)

Fig. 6. Backbones of the temperature-sensitive hydrogel in the (a) swollen and (b) aggregated condition [41]

A thermo-responsive copolymer derivative utilizing keto-enol tautomerization is disclosed in a patent EP 922715 containing N-acetylacrylamide-methacrylamide-N,N'-methylene bisacrylamide. In particular, this copolymer is a composite stimuli-responsive polymer which has both an UCST and a LCST within various temperature ranges, and also responds to hydrogen ion concentration. Accordingly, it can be effectively used for chemovalve, for separation, drug delivery systems, catheters, artificial muscles, etc. [47]. A hybrid nanogel has been developed based on interpenetrating networks of pNIPAM gels and tailored nanoporous silica. The overall drug release rate can be adjusted by changing the composition of the nanogel [48]. The graft polymers are obtained by grafting gelatin with pNIPAM under UV radiation to obtain a cell culture substrate [49]. Hydrogel prepared by polymerizing $N$-alkyl-substituted (meth)acrylamide NIPAM and a functional group-containing monomer $N$-acryloxysuccinimide with a cross-linking agent azobisisobutyronitrile, can control the medicine discharge, responding to specified temperature change [50].

The biodegradable copolymers based on pNIPAM, polyacrylamide, polydimethylacrylamide, or a block copolymer based on polyethylene glycol and polypropylene glycol are useful as drug carriers, comprise three-dimensional network structure wherein a temperature-responsible polymer is introduced [51]. Thermally reversible hydrophilichydrophobic copolymer comprise structure units derived from at least one monomer selected from $N$-n-propylacrylamide, NIPAM, and $N, N$-diethylacrylamide and surfactants were copolymerized by Ito [52].

\section{2. pH-sensitive hydrogels}

$\mathrm{pH}$-Sensitive polymers are water-soluble with ionizing functional groups. Their physical properties, such as solubility, change in terms of $\mathrm{pH}$. Ever since the first report on the phase transition of $\mathrm{pH}$-sensitive polymers appeared, many of $\mathrm{pH}$-sensitive polymers have been developed [7].

$\mathrm{pH}-$ Sensitive hydrogels can be grouped in two main classes: cationic hydrogels and anionic hydrogels. Cationic hydrogels swell and release a drug into a low-pH environment of stomach. There is a minimal swelling of anionic hydrogels in the stomach and that is why the drug release is also minimal. As the hydrogel begins to travel through the intestinal tract, the swelling increases, due to $\mathrm{pH}$ increase in, leading to ionization of carboxylic groups. But the azoaromatic crosslinks of the hydrogels can be degraded only by azoreductase produced by the microbial flora of the colon $[53,54]$, as shown in Figure 7. 
The degradation kinetics and degradation pattern can be controlled by the cross-linking density. The pH-sensitive copolymer $N$-methacrylamido- $N$ '-(6-methoxy-3-pyridazonyl)sulfonamide is prepared by introduction of sulfonamide groups, various in $\mathrm{pKa}$, to hydrophilic groups of polymers either through coupling into the hydrophilic groups, such as acrylamide, $N, N$-dimethylacrylamide, acrylic acid, NIPAM etc., of polymers, or copolymerization with other polymerizing monomers. These $\mathrm{pH}$-sensitive polymers can change in physical properties, such as solubility and swelling properties depending on $\mathrm{pH}$, and may have a structure of linear polymer, grafted copolymer, hydrogel or interpenetrating network polymer, can be applied for a drug-delivery systems, bio-material, sensors, etc. [55].

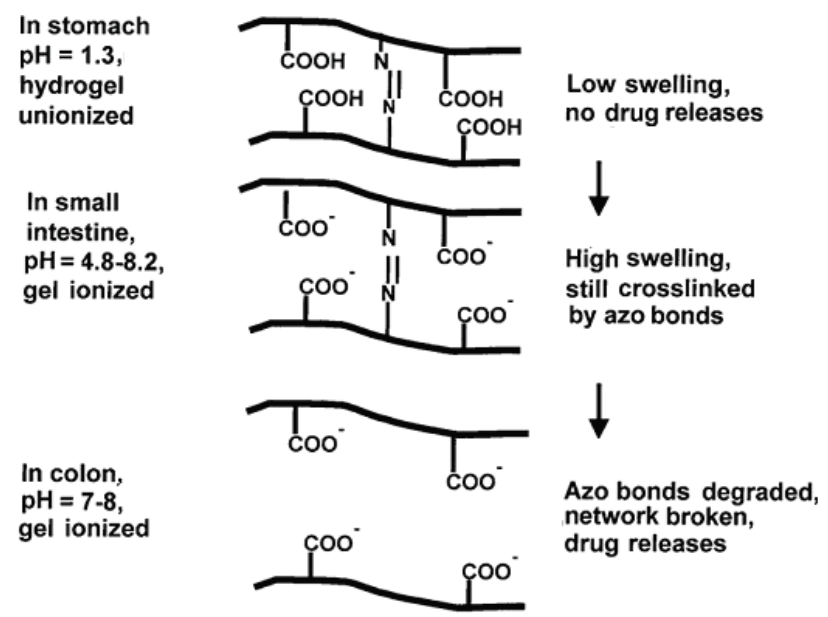

Fig. 7. Schematic illustration of oral colon-specific drug delivery using biodegradable and $\mathrm{pH}$ sensitive hydrogels [53]

Manipulation of hydrogel structure has produced stimuli-sensitive hydrogels, which change their swelling degree or undergo phase transition in response to minimal changes in environmental conditions [56]. Introduction of ionogenic groups into EDMA crosslinked HEMA hydrogels permitted control of their permeability as a function of $\mathrm{pH}$ [57] and specific resistance [58]. Krušić et al. [59] have investigated hydrogel membranes containing methacrylic acid units semi-interpenetrating polymer networks of poly(ethylene glycol) in poly(acrylamide-co-itaconic acid).

\subsection{Dual pH-thermal sensitive systems}

A new type of $\mathrm{pH}$ and temperature-sensitive copolymer based on pNIPAM with $\mathrm{N}$ acryloxysuccinimide and $N$-[4-(1-pyrenyl)butyl]- $N$-n-octadecylacrylamide contains temperature- and $\mathrm{pH}$-responsive groups, as well as hydrophobic groups. A drug delivery composition, consisted of phospholipids liposomes (dimyristoyl phosphatidylcholine, cholesterol, dimethyl dioctadecylammonium bromide) and non-phospholipids liposomes (n-octadecyl diethylene oxide) are disclosed [60]. The invention WO 2007/063320 describes the polymer mixture, a combination of thermo-responsive diblock copolymer incorporating with pHPMet. The polymer unit NIPAM exhibits an increase in hydrophobicity by changing the temperature or $\mathrm{pH}$ of aqueous environment [61]. 
The $\mathrm{pH}$ - and temperature-sensitive polymer-based microbeads are manufactured and presented in JP 11080701 [62]. Yao [63] invented an intelligent nano-gel for medicine that has a core-shell structure composed of thermo-sensitive high-molecular polyose as core, and pH-sensitive acrylic polymer as shell, prepared through adding acrylic acid or its derivative to the aqueous suspension of polyose nanoparticles, filling $\mathrm{N}_{2}$, deoxidizing, adding cross-linking agent and trigger. An environment responsive binary intelligent gel with high hydroscopicity and swelling ratio and the response power to ambient temperature and $\mathrm{pH}$ value is prepared from 2-acrylamide-2-methyl propanesulfonic acid and NIPAM showed in CN 1869087 [32]. Okano and collaborators [64] invented a copolymer based on poly(NIPAM-N,N-dimethylaminopropyl-acrylamide) and made it possible to change the effective charge density or hydrophilic/hydrophobic balance on the surface of a stationary phase in an aqueous system by an external signal (temperature, $\mathrm{pH}$ ). The NIPAM-methacrylic acid/zirconium dioxide microgel has sensibility to temperature and $\mathrm{pH}$, with special absorption to proteins, and can be used for separating proteins [26]. $\mathrm{pH}-$ Thermo-responsive hydrogels of NIPAM and acrylic acid (AAc) were investigated [27]. Zhang [65] showed one kind of temperature-sensitive and $\mathrm{pH}$-sensitive gel, which solidifies at temperature above $33^{\circ} \mathrm{C}$ and expands fast at $\mathrm{pH}$ above 6.0 to absorb water.

\subsection{Other stimuli-sensitive hydrogels}

The identification and determination of various biologically relevant substances' concentrations are of great importance for biomedical applications. For this purpose, the use of hydrogels sensitive to analytes may be helpful, if they function under physiologically relevant temperatures, $\mathrm{pH}$, and ionic strength. Different kinds of gels responding to external fields have been proposed, especially to be used in externally regulated systems to deliver drugs [66]. The concept is based on the fact that stimuli such as magnetic or electric fields, ultrasound, irradiation or electric effects, may trigger the release of some therapeutic molecules from a previously implanted hydrogel-based devise. Other biomedical applications can be envisaged because such effects can be converted into mechanical action as the gels can swell, shrink or bend, enabling their use as artificial muscles [67].

Among the stimulus responsive analytes are mono- and disaccharides, enzymes, antigens, and various ions [68]. Biomolecule-sensitive hydrogels that undergo swelling changes in response to specific biomolecules can be modified to design smart hydrogels that could degrade in response to increase in concentration of specific biomolecules [69]. The measurement of glucose is extremely important in the treatment of diabetes and is also of value in monitoring cell growth, since glucose is the primary carbon source in most fermentation processes [70]. Therefore, precisely engineered glucose-sensitive gels have huge potential in the quest to generate self regulated modes of insulin delivery and to facilitate the construction of an artificial pancreas which would function in a manner similar to the $\beta$-cells of the pancreas. Conventionally, glucose oxidase (GOx) based biosensors have been used in monitoring blood glucose levels in diabetic patients. Detection of blood glucose levels is achieved via the electrochemical detection of blood glucose levels using a "finger-stick" apparatus. This method is based on the indirect electrochemical detection of hydrogen peroxide generated by the oxidation of glucose with GOx [71].

Pressure might induce volume phase transition in hydrogels and therefore is used in fabrication of pressure-sensitive drug delivery systems [5]. Pressure-responsive and ionic strength-responsive hydrogels are actually thermo - or/and $\mathrm{pH}$-responsive, in which response to changes in temperature or $\mathrm{pH}$ is modified significantly by changing the 
pressure or ionic strength of a solution [68, 71]. This may, sometimes, be true for the light or electric impulse-responsive hydrogels too. However, in this case, effects induced by light or electric pulse might be much larger.

Ultrasound is widely employed as a drug permeation enhancer through biological barriers. Pulsatile drug delivery can be achieved by the on/off application of ultrasound to an ultrasound-sensitive hydrogel. Pulsatile release of insulin was observed only after ultrasonic exposure for 1 minute, which caused perturbation of self-assembled methylene chains, causing release of insulin [5].

Magnetically responsive hydrogels can be prepared by growing PHEMA from the surface of $\mathrm{Fe}_{3} \mathrm{O}_{4}$ magnetic particles for the use in separations [72, 73]. The invention WO 99/35500 concerns the preparation and application of magnetic particles covered with functionalized polymer coatings that possess a lower critical solubility temperature and are able to bind proteins and nucleic acids. The polymer coating consist of a middle and an outer layer; the middle layer is composed of a functionalized or non-functionalized polymer forming monomer and a cross-linking agent; the outer layer is made of a functionalized or non-functionalized polymer forming monomer and the initiator. For nucleic acid immobilization and determination, the particles are operated below LCST; for protein binding the temperature is kept above LCST, and for the following analysis the temperature is lowered below LCST. The polymerization can be performed in batch mode or continuous mode [74].

Light-responsive hydrogels cover budding applications in developing photo-responsive devices, especially in ophthalmic drug delivery systems [5]. Light-responsive systems possess a potential of becoming truly biomimetic sensors or actuators [75]. Photoinduced self-healing polymers can mimic the biological systems in which damage triggers a self-healing response. These materials can be used to repair fiber fracture, delamination or propagation of microcracks of polymeric components used in a variety of applications, extending the functional life and safety of the polymeric components [76, 77]. On the other hand, some polymers such as segmented polyurethanes that are able to undergo light-induced shape changes can imitate the movement of artificial muscles [78, 79]. Another example of light responsive systems is „gated" membranes controlling the transport of ions or the flow of gases or liquids through microchannels [80, 81]. Monodisperse pNIPAM-allylamine copolymer microgels with photo-, thermally, and $\mathrm{pH}$-responsive properties in aqueous suspension have been synthesized using a precipitation polymerization method. The new route involved first preparing pNIPAM-allylamine copolymer microgels and a spiropyran photochrome (SP) bearing a carboxylic acid group. The microgels undergo a volume phase transition in water from a swollen state to a collapsed state with increasing temperature under all light conditions. Due to the residues of amine groups, the swelling capability of pNIPAM-SP microgels reduces as the $\mathrm{pH}$ value is changed from 7 to 10 [82]. A photoresponsive hydrogel composed of pNIPAM partly modified with spirobenzopyran and observed that the hydrogel in acidic conditions exhibited drastic and rapid volume shrinkage and proton dissociation when it was irradiated with blue light. Since the light can be irradiated in a precision of micrometerscale, this hydrogel is considered to be a feasible material out of which to construct photoresponsive devices to control the mass transfer or ionic conditions in microfluidic systems [33]. 


\section{Pharmaceutical AND MEdicAl APPliCATION OF HydROgElS}

The effect of hydrogels on pharmacy and medicine is generally recognized because of their biocompatibility and biodegradability. Hydrogels were the first biomaterials rationally designed for human consumption and play a crucial role in controlling drug release rate, increasing the drug solubility, and limiting drug degradation and toxicity. Multiple competence strategies incorporating diversified research fields are now progressing to develop cures for disease and disorders. Tissue engineering, imunoisolation individually or synergistically and drug delivery provide opportunities to design intelligent hydrogelbased systems for medical and pharmaceutical applications.

\subsection{Pharmaceutical applications of hydrogels}

Hydrogels have been used for the development of controlled delivery systems for a long time. When the drug bearing hydrogel comes in contact with aqueous medium, water penetrates into the system and dissolves the drug. Diffusion is the main phenomena by which the dissolved drug diffuses out of the delivery systems to the surrounding aqueous medium. Diffusion is defined as the movement of the individual molecules from the region of high solute concentration to a region of low concentration when the systems are separated by a polymeric membrane [2]. The invention WO 2007/063320 relates to a pharmaceutical composition for the treatment of cancer comprising a temperature dependent polymer gelator and a therapeutic amount of a chemotherapeutic agent [61]. Release profile of caffeine drug and NSAID (paracetamol, ibuprofen, phenacetin, naproxen, piroxicam) behaviors from NIPAM/HPMet hydrogel were investigated [27-28]. A method of treating an animal in need of a therapeutic agent comprising administering a drug delivery composition comprising liposomes is described in patent CA 2254554 [60]. The acoustically activated micellar doxorubicin delivery was an effective method for targeted delivery of drugs to solid tumors. This method is disclosed in WO 2000/069942 in which a micelle is stabilized against degradation upon dilution. The micelle comprises a block polymer having a hydrophobic block and a hydrophilic block. A substance such as drugs can be incorporated into the dense inner core of the micelles [83].

Conventional methods of drug loading in hydrogel systems are limited by the characteristics of the pharmacological agent. Hydrophobic components are often included to overcome problems related to loading hydrophobic drugs into hydrophilic hydrogels. Cyclodextrin complexes can improve delivery of hydrophobic drugs from swellable systems on simple and effective technique. It may be inserted into hydrogels in order to isolate the hydrophobic drugs in the inclusion complexes. Results of paeonol- $\beta$-cyclodextrin complex release experiments indicated that the release of complex is related to the volume contraction of pNIPAM hydrogel, which was affected by hydrogel compositions and release temperatures [84-86]. This is owing to those CDs, cyclic oligosaccharides whose molecules have hydrophilic outer surfaces and a hydrophobic cavity at the center (Figure 8), can function as host molecules to include hydrophobic drugs (guest molecules) to form water-soluble CD drug complexes [86]. 
(a)

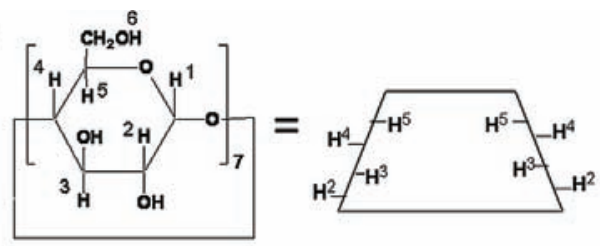

(b)

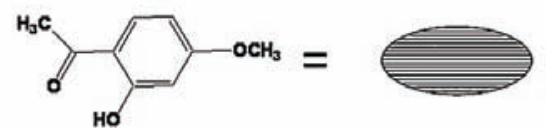

(c)

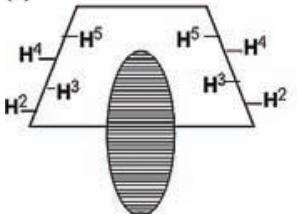

(d)

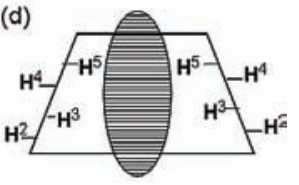

Fig. 8. Chemical structures: (a) $\beta-C D$, (b) PAE, possible models of entry of PAE into $\beta-C D$ cavity, (c) PAE partially inside $\beta$-CD cavity, (d) PAE deeply inside $\beta$-CD cavity [86]

The highly porous structure of hydrogels enables introduction of a relatively large load of drugs into them. Enzymatic, hydrolytic, or environmental pathways may be used to biodegrade the hydrogels [87]. The copolymers consisting of styrene HEMA and NIPAM is used in drug delivery systems and enzyme [37]. The problem of loading hydrogels with hydrophobic drugs may also be approached by copolymerization of hydrophilic hydrogels with hydrophobic segments, or by the use of amphiphilic interpenetrating polymer network (IPNs) in which a hydrophobic component is interpenetrated by a hydrophilic one or vice versa [88, 89].

Zhang [65] showed one kind of 'intelligent' gel and its application in contraception, which may be used as the carrier of spermaticide or semen coagulator and may be administrated through male's urethra or female's vagina. Another US patent describes a class of semi-interpenetrating polymeric networks that includes linear polymer molecules functionalized with a bioactive moiety. The linear polymer is physically entangled with the bioactive moiety. The polymer network, which can be used as a matrix in tissue engineering, is fluid at room temperature, but becomes solid or semisolid at elevated temperature, e.g. at mammalian body temperatures [90].

Patent application US 2006/0135911 describes a transbody-surface drug delivery device for the administration of bioactive molecules to an individual at a therapeutically effective rate. The system comprises a thermo-responsive gel based on a poly(NIPAMacrylamide), synthesized by the free radical solution copolymerization, with the capability of reversibly swelling and de-swelling to control the release of embedded bioactive molecules. Transdermal drug delivery can generally be considered to belong to one of two groups: transport by a "passive" mechanism or by an "active" electrotransport mechanism [91]. 


\subsection{Medical application of hydrogels}

Hydrogels have also been designed for augmenting vocal cords [92], prevention of scar formation after surgery and as coverings for perforated ear drums and rhinoplasty. These applications were the driving force that initiated a detailed study on the relationship between the structure of cross-linked hydrophilic polymers and their biocompatibility [93-97]. These results were translated into clinical applications: one of the successful examples was the use of HEMA-based hydrogels in rhinoplasty (Figure 9), which produced long-term biocompatibility and excellent cosmetic results [98].
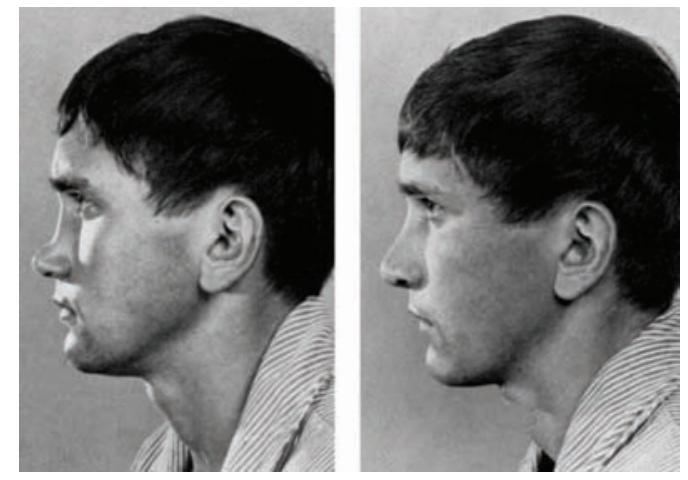

Fig. 9. Use of hydrogels (copolymers of HEMA with EDMA) in rhinoplasty:

(a) patient before surgery; (b) patient after surgery [98]

In ophthalmology, along with soft contact lenses, glaucoma microcapillary drain, fillings for the restoration of detached retina were studied [12, 14-17, 99]. A soft and flexible contact lenses for correcting refraction errors of the eye is prepared by polymerizing a mixture of ethyleneglycol monomethacrylate in the absence of solvents capable of swelling the polymer, were disclosed in the patent US 3,496,254 [100]. According to the invention, lenses are ground to a spherical surface from a polymer having plastic memory, aspherical surface from a sparingly cross-linked polymer [101].

A chemical responsive valve disclosed in EP 562,303 has a porous matrix and also a gel layer release surface, stimulated by the surrounding conditions to be opened or closed by dilation or contraction of its pores. The matrix is a microporous membrane consisting of a copolymer of diethyleneglycol bisallyl carbonate and methacryloyl-L-alamine methyl ester. So called "intelligent polymers" with permeability responding to such ambient conditions as $\mathrm{pH}$, temperature, or conductivity etc., allowing the use as "chemical valves" e.g. as release means for medicaments within the body [102].

The invention US 3,862,452 relates to substitutes for tubular somatic organs and a method of preparing the same. The outer covering comprises a hydrogel polymerized about the textile made from physiologically harmless synthetic fibers. Analogously to the method of producing arterial substitute it is possible to prepare substitutes for veins, lymphatic ducts, biliary ducts, trachea, acoustic ducts, oviducts (Fallopian tubes) or renewal of free passage there through, ophthalmologic bandage for therapy of separated retina, protective capsule for nerve bundles, or the like. For this purpose there is suitable a physiologically inert high linear polymer having a great value of molecular mass, as for example, non-cross-linked polymeric ethyleneglycol methacrylate [103]. 
The invention WO 99/49908 relates to the delivery of biologically active solute materials to target locations within a mammalian body using thermosensitive cellulose gels (hydroxypropyl cellulose gels, hydroxypropylmethyl cellulose gels, ethylhydroxyethyl cellulose gels, carboxymethyl cellulose gels, hydroxyethyl cellulose gels, methyl cellulose gels, ethyl cellulose gels, propyl cellulose gels, butyl cellulose gels). The temperature controlled solute delivery system used comprises a medical device as stent, or balloon catheter. An increase of the gel temperature leads to a de-swelling together with a release of the solute [104].

Porous polymer monoliths based on $\mathrm{N}$-isopropylacrylamide are made thermally responsive by grafting the pores with thermally responsive polymers and copolymers. Depending on the reaction conditions employed, the grafted polymer can either completely block flow through micrometer-sized pores in the monoliths or control the flow rate through the monoliths. The grafted monoliths are useful as thermal gates, thermal valves, and for isocratic hydrophobic interaction chromatography of proteins [105]. A method and apparatus based on hydroxyethyl methacrylate for introducing fluids into the body and in particular to an implant in which the introduction of liquid by injection can be facilitated is invented by Wichterle [106].

A medical device containing a thermo-sensitive cellulose gel structure, which can deliver a bioactive-solute compound to a target location in the body, is described in the patent US 6,733,788. The gel structure de-swells at a certain temperature and expels the biologically active solute upon an increase in gel temperature. The shrinking cellulose gel releases the solute in a sustained, convective release pulse such that substantially all of the loaded solute is released in a relatively short time under the influence of increased body temperature. They can be applied as a coating a balloon catheter with cellulose gels that can rapidly expel biologically active solutes when the gels are heated, particularly above their transition temperatures [107]. An intralumenal implant material, based on butylmethacrylate-NIPAM-methacryloyl isocyanate copolymer shows a substantial water-insolubility at a temperature higher than the sol-gel transition temperature, and shows thermo-reversible water-solubility at a temperature lower than the sol-gel transition temperature. It is capable to be endovascularly or percutaneously delivered into a vascular lumen in a liquid state at the temperature lower than the sol-gel transition temperature, is capable to be instantly converted into a gel state in the vascular lumen at the blood temperature higher than the sol-gel transition temperature and is capable of occluding aneurysms, vascular tumors or vascular malformation. It shows excellent biocompatibility and mechanical matching for the vascular tissue and the surrounding tissue [108].

The invention WO 99/55386 disclosed a thermally reversible stimulus-sensitive gel or gelling copolymer radioisotope carrier that is a linear random copolymer of a methacrylamide derivative and a hydrophilic comonomer. The gel is enhanced by either combining it with a biodegradable backbone and/or a therapeutic agent in a gelling solution made by mixing the copolymer with an aqueous solvent. This experiment showed excellent localization of radioisotope polymer composite in the target tissue (prostate) of dog with minimal radionuclide activity in other non-target tissues [109].

Synthesis of $N$-isopropylacrylamide/polyacrylamide interpenetrating network is described in US 5,976,648. The heterogeneous polymer gel is characterized in that it exhibits changes in volume in response to external environmental changes. The device comprising a heterogeneous polymer gel comprises first gel layer comprising an environmentally-stable gel; and a second gel layer comprising an environmentally-unstable gel, 
which can be used as the device comprises an artificial muscle, a drug-delivery device, a chemical valve or actuator [110]. Segmented polyurethanes are able to undergo lightinduced shape changes can imitate the movement of artificial muscles, the shape-memory polymers being useful for medical devices that can recover a certain form by a remote light activation $[111,112]$.

\section{CONCLUSIONS}

The utilization of hydrogels has made a great progress in the last 50 years. Traditional materials design concepts were tailored to provide novel biomaterials with unique properties. In this review, intelligent polymeric gels were classified on the basis of structural properties. Next, they were classified on the basis of the types of stimuli the gels respond to. Design of intelligent materials has been studied for many years, but many new elegant concepts have continuously been reported that could extend or improve their applicability in the biomedical field. Just a few representative examples in this context have been presented to provide a general overview of their applicability on smart delivery systems, either controlled externally or self-regulated, tissue engineering and regenerative medicine. Much work is still to be done in order to improve the communication between materials and the biological environment, so that the clinical applicability of such devices could have success.

\section{REFERENCES}

1. J. Jagur-Grodzinski, Polymeric gels and hydrogels for biomedical and pharmaceutical applications, Polymers for Advanced Technologies, 21 (1), 27-47 (2010).

2. K. Pal, A.K. Banthia and D.K. Majumda, Polymeric hydrogels: characterization and biomedical applications - A mini review, Designed Monomers and Polymers, 12 (3), 197-220 (2009).

3. A.S. Hoffman, Hydrogels for biomedical applications, Advanced Drug Delivery Reviews, 54 (1), 312 (2002).

4. S. Chaterji, I.K. Kwon and K. Park, Smart polymeric gels: Redifining the limits of biomedical devices, Progress in Polymer Science, 32 (8-9), 1083-1122 (2007).

5. N. Kashyap, N. Kumar and M.N.V. Ravi Kumar, Hydrogels for pharmaceutical and biomedical applications, Critical Reviews in Therapeutic Drug Carrier Systems, 22 (2), 107-150 (2005).

6. The Chemical Industry and its Development (Opinion), Nature 165 (4194), 413-415 (1950).

7. H.W. Coover and N.H. Shearer, $N$-substituted acrylamides by vapor phase method using acrylic acids, US 2719177, 1953.

8. M. Heskins and J.E. Guillet, Solution properties of poly( $N$-isopropylacrylamide), Journal of Macromolecular Science, Part A: Pure and Applied Chemistry, 2 (8), 1441 -1455 (1968).

9. O. Wichterle and D. Lìm, Hydrophilic gels for biological use, Nature, 185 (4706), 117-118 (1960).

10. O. Wichterle and D. Lìm, Process for producing shaped articles from three-dimensional hydrophilic high polymers, US 2976576, 1956.

11. O. Wichterle, Contact lens, BE 633091, 1962.

12. O. Wichterle, Anhydrous sparingly cross-linked hydrophilic copolymers, US 3699089, 1972.

13. O. Wichterle, Reshaping a xerogel by mechanical removal and swelling to form a hydrogel contact lens, US 3361858, 1968.

14. O. Wichterle, Soft contact lens with thin edge, US 4153349, 1979

15. M. Dreifus, O. Wichterle and D. Lìm, Intra-cameral lenses made of hydrocolloidal acrylates, Československá oftalmologie 16, 154-159 (1960). 
16. M. Dreifus, T. Herben, D. Lìm and O. Wichterle, Tolerance of orbital implants made of hydrocolloid acrylate, Sborník lékaršký, 62, 212-8 (1960).

17. C. Alvarez-Lorenzo, L. Bromberg and A. Concheiro, Light-sensitive intelligent drug delivery systems, Photochemistry and photobiology, 85 (4), 848-860 (2009).

18. R.M. Ottenbrite, K. Park, T. Okano and N.A. Peppas, Biomedical Applications of Hydrogels Handbook, Springer, New York, 2010.

19. I. Shoji, M. Kensaku, F. Norinaga and S. Masao, Production of heat-sensitive polymer compound, JP 63117017, 1988.

20. T. Okuhara and K. Urabe, Preparation of NIPAM, JP 2000/264864, 2000.

21. I. Shoji, M. Kensaku and F. Norinaga, Production of heat-sensitive polymer, JP 63117016, 1986

22. G. Masci, L. Giacomelli and V. Crescenzi, Atom Transfer Radical Polymerization of NIPAM, Macromolecular Rapid Communication, 25 (4), 559-564 (2004).

23. L. Xiaohua, W. Xiaogong and L. Deshan, Process for preparing temp-sensitive porous poly $(N-$ isopropyl acrylamide) aqueogel, $C N$ 1328067, 2001.

24. A.A. Sanford and L. Lei, Hydrogels with crystalline colloidal array of water voids for macromolecule separations and detection, WO 2000/000278, 2000.

25. J. Hu, Y. Zhang, Properties and characteristics of hydrogels, CN 101704925, 2009.

26. R. Kishi, T. Miura, H. Kihara, T. Asano, M. Shibata and R. Yosomiya, Journal of applied polymer science, 89 (1), 75-84 (2003).

27. S. Ilić-Stojanović, Lj. Nikolić, V. Nikolić, S. Petrović and M. Stanković, Process for synthesis of thermosensitive hydrogels and pharmaceutical applications, RS-P-2010/0424, 2010.

28. H.M. Nizam El-Din, Characterization and caffeine release properties of $N$-isopropylacrylamide /hydroxypropyl methacrylate, copolymer hydrogel synthesized by gamma radiation, Journal of Applied Polymer Science, 119 (1), 577-585 (2011).

29. Z. Zhao, Z. Li, Q. Xia, H. Xi and Y. Lin, Fast synthesis of temperature-sensitive PNIPAAm hydrogels by microwave irradiation, European Polymer Journal, 44 (4), 1217-1224 (2008).

30. A.L. Yarin and Y. Zhang, Stimuli-responsive low solubility hydrogel copolymers of $N$-isopropyl acrylamide and synthesis method, US 2010/203141, 2010.

31. I. Akiji, Manufacture of $\mathrm{pH}$ - and heat-sensitive (meth)acrylic acid polymer-based microbeads, JP $11080701,1999$.

32. C. Xiaoguang, G. Cui, S. Dong, Y. Wu and B. Zhang, Environment response dielement intelligent gel and its preparation method, CN 1869087, 2006.

33. K. Sumaru, K. Ohi, T. Takagi, T. Kanamori and T. Shinbo, Photoresponsive properties of poly(NIPAM) hydrogel partly modified with spirobenzopyran, Langmuir, 22 (12), 4353-4356 (2006).

34. Y. Zhao, Y. Yang, X. Yang and H. Xu, Preparation and $\mathrm{pH}$-sensitive swelling behavior of physically crosslinked polyampholyte gels, Journal of Applied Polymer Science, 102 (4), 3857-3861 (2006).

35. A. Patel and K. Mequanint, Novel physically cross-linked polyurethane block-poly(vinyl pyrrolidone), hydrogel biomaterials, Macromolecular Bioscience, 7 (5), 727-737 (2006).

36. K. Mequanint, A. Patel and D. Bezuidenhout, Synthesis, swelling behavior, and biocompatibility of novel physically cross-linked polyurethaneblock-poly(glycerol methacrylate) hydrogels, Macromolecules, 7 (3), 883-891 (2006).

37. B. Samra, I. Galaev and B. Mattiasson, Gels with a shape memory, WO 2000/046262, 2000.

38. N.B. Graham, Polyethylene glycol chemistry. In: J.M. Harris (Edt), Biotechnical and biomedical application, Plenum Press, New York, 1992, 1-13.

39. N.A. Peppas, P. Bures, W. Leobandung and H. Chikawa, Hydrogels in pharmaceutical formulations, European journal of pharmaceutics and biopharmaceutics, 50 (1), 27-46 (2000).

40. J. Heiko, L. Vander, H. Sebastiaan, O. Wonter and B. Piet, Stimulus-sensitive hydrogels and their application in chemical (micro) analysis, Royal society of chemistry, 128, 325-331 (2003).

41. A.K. Bajpai, S.K. Shukla, S. Bhanu and S. Kankane, Responsive polymers in controlled drug delivery, Progress in Polymer Science, 33 (11), 1088-1118 ( 2008).

42. E.S. Gil and S.M. Hudson, Stimuli-responsive polymers and their bioconjugates, Progress in Polymer Sciences, 29 (12), 1173-222 (2004).

43. B. Yıldız, B. Işik and M. Kış, Synthesis and characterization of thermoresponsive isopropylacrylamide-acrylamide hydrogels, European Polymer Journal, 38 (7), 1343-1347 (2002). 
44. B. Ișik and Y. Günay, Synthesis and characterization of thermoresponsive poly( $N$-isopropylacrylamideco- $N$-hydroxymethylacrylamide-co-2-hydroxyethyl methacrylate) hydrogels, Colloid Polymer Science, 282 (1), 693-698 (2004).

45. Z. Shen, K. Terao, Y. Maki, T. Dobashi, G. Ma and T. Yamamoto, Synthesis and phase behavior of aqueous poly( $N$-isopropylacrylamide-co-acrylamide), $\operatorname{poly}(N$-isopropylacrylamide-co- $N, N$ dimethylacrylamide) and poly ( $N$-isopropylacrylamide-co-2-hydroxyethyl methacrylate), Colloid Polymer Science 284 (9), 1001-1007 (2006).

46. M. Andersson, A. Axelsson and G. Zacchi, Swelling kinetics of poly( $N$-isopropylacrylamide) gel, Journal of Controlled Release, 50 (1-3), 273-281 (1998).

47. N. Ohnishi, K. Aoshima, K. Kataoka and K. Ueno, Stimuli-responsive polymer utilizing keto-enol tautomerization for pharmaceutical and medical use, EP 922715, 1999.

48. Y. Shin, J.H. Chang, J. Liu, R. Williford, Y.K. Shin and G.J. Exarhos, Journal of Controlled Release, 73 (1), 1-6 (2001).

49. T. Matsuda and N. Morikawa, Thermally sensitive gelatin graft polymers, their manufacture and use in cell culture substrates, JP 11349643, 1999.

50. T. Kimura and K. Takagi, Temperature response-type $N$-alkyl(meth)acrylamide-based hydrogels, JP 11189626, 1999.

51. N. Yui, Temperature-responsive biodegradable polymers providing novel drug delivery systems, JP 11322941, 1999.

52. S. Ito, Copolymer having reversible hydrophilicity-hydrophobicity transition and its production, JP 3101714, 2000.

53. H. Ghandehari, P. Kopeckova and J. Kopecek, In vitro degradation of $\mathrm{pH}$ sensitive hydrogels containing aromatic azobonds, Biomaterials, 18 (12), 861-872 (1997).

54. E.O. Akala, P. Kopeckova and J. Kopecek, Novel pH-sensitive hydrogels with adjustable swelling kinetics, Biomaterials, 19 (11-12), 1037-1047 (1998).

55. Y. Bae and S.Y. Park, pH-Sensitive polymer containing sulfonamide and its synthesis method, US 6103865, 2000.

56. K. Dušek and D. Patterson, Transition in swollen polymer networks induced by intramolecular condensation, Journal of Polymer Science Part A-2: Polymer Physics, 6 (7), 1209-1216 (1968)

57. J. Kopeček, J. Vacìk and D. Lìm, Permeability of membranes containing ionogenic groups, Journal of Polymer Science Part A-1: Polymer Physics, 9 (10), 2801-2815 (1971).

58. J. Vacik and J. Kopeček, Specific resistances of hydrophilic membranes containing ionogenic groups, Journal of Applied Polymer Science, 19 (11), 3029-3044 (1975).

59. M.K. Krušić, D. Danković, M. Nikolić and J. Filipović, Poly(acrylamide-co-itaconic acid) and semi-IPNs with poly(ethylene glycol): Preparation and characterization, Macromolecular Chemistry and Physics, 205 (16), 2214-2220 (2004).

60. A. Polozova, F.M. Winnik and D.W. Andrews, Novel non-phospholipid liposomes modified with a $\mathrm{pH}$ and temperature sensitive copolymer, CA 2254554, 2000.

61. S.P. Armes, P.J. Madsen, C.D. Vo and C. Li, Polymer gelator, WO 2007/063320, 2007.

62. I. Akiji, Manufacture of $\mathrm{pH}$ - and heat-sensitive (meth)acrylic acid polymer-based microbeads, JP $11080701,1999$.

63. R.X. Yao, Medical intelligent nano-gel material and its preparation method, CN 1718616, 2006.

64. T. Okano, A. Kikuchi, Y. Sakurai, H. Kanazawa and Y. Matsushima, Packing material for chromatography having novel characteristic and method for isolation of substance using the same, EP 1081492, 2000.

65. W. Zhang, 'Intelligent' gel and its application in contraception, CN 1887253, 2007.

66. J. Kost and R. Langer, Responsive polymeric delivery systems, Advanced Drug Delivery Reviews, 46 (1-3), 125-148 (2001).

67. J. Shang, X. Chen and Z.Z. Shao, The electric-field-sensitive hydrogels, Progress in Chemistry, 19 (9), 1393-1399 (2007).

68. Y. Qiu and K. Park, Environment-sensitive hydrogels for drug delivery, Advanced Drug Delivery Reviews, 53 (3), 321-339 (2001).

69. T. Miyata, T. Uragami and K. Nakamae, Biomolecule-sensitive hydrogels, Advanced Drug Delivery Review, 54 (1), 79-98 (2002). 
70. S. Kabilan, J. Blyth, M.C. Lee, A.J. Marshall, A. Hussain, X.P.Yang and C.R. Lowe, Glucosesensitive holographic sensors, Journal of Molecular Recognition, 17 (3), 162-166 (2004).

71. K.E. Shafer-Peltier, C.L. Haynes, M.R. Glucksberg and R.P. Van Duyne, Toward a glucose biosensor based on surface-enhanced Raman scattering, Journal of American Chemical Society, 125 (2), 588-593 (2003).

72. S.K. Ahn, R.M. Kasi, S.C. Kim, N. Sharma and Y. Zhou, Stimuli responsive polymer gels, Soft Matter, 4 (6), 1151-1157 (2008).

73. T. Gelbrich, M. Feyen and A.M. Schmidt, Magnetic thermoresponsive core-shell nanoparticles, Macromolecules, 39 (9), 3469-3472 (2006).

74. A. Elaissari, C. Pichot and B. Mandrand, Improved magnetic particles, method for obtaining same and uses for separating molecules, EP 1046037, 1999.

75. C. Barrett and O. Mermut, Polymer multilayer films with azobenzene for photoactive biosurfaces, PMSE Preprints, 92, 51-52 (2005).

76. C.M. Chung, Y.S. Roh, S.Y. Cho and J.G. Kim, Crack healing in polymeric materials via photochemical [2 + 2] cycloaddition, Chemistry of Materials, 16 (21), 3982-3984 (2004).

77. D.Y. Wu, S. Meure and D. Solomon, Self-healing polymeric materials: A review of recent developments, Progress in Polymer Science, 33 (5), 479-522 (2008).

78. H. Jiang, S. Kelch and A. Lendlein, Polymers move in response to light, Advanced Materials, 18 (11), 1471-1475 (2006) .

79. A. Lendlein, H. Jiang, O. Junger and R. Langer, Lightinduced shape-memory polymers, Nature, 434 (7035), 879-882 (2005).

80. R. Rosario, D. Gust, M. Hayes, F. Jahnke, J. Springer and A.A. Garcia, Photon-modulated wettability changes on spiropyran-coated surfaces, Langmuir, 18 (21), 8062-8069 (2002).

81. M. Kameda, K. Sumaru, T. Kanamori and T. Shinbo, Photoresponse gas permeability of azobenzene-functionalized glassy polymer films, Journal of Applied Polymer Science, 88 (8), 2068-2072 (2003).

82. A. Garcia, M. Marquez, T. Cai, R. Rosario, Z. Hu, D. Gust, S. Hayes, A.C. Vail and D. Park, Photo thermally and pH-responsive microgels, Langmuir, 23 (1), 224-229 (2007).

83. N. Rapoport and W.G. Pitt, Stabilization and acoustic activation of polymeric micelles for drug delivery, WO 2000/069942, 2000.

84. D. Kanjickal, S. Lopina, M.M. Evancho-Chapman, S. Schmidt and D. Donovan, Improving delivery of hydrophobic drugs from hydrogels through cyclodextrins, Journal of Biomedical Materials Research, 74A (3), 454-460 (2005).

85. Y.Y. Liu, X.D. Fan, T. Kang and L. Sun, Cyclodextrin microgel for controlled release driven by inclusion effects, Macromolecular Rapid Communications, 25 (22), 1912-1916 (2004).

86. J.Y. Tsao, H.H. Tsai, C.P. Wu, P.Y. Lin, S.Y. Su, L.D. Chen, F.J. Tsai and Y. Tsai, Release of paeonol- $\beta$-CD complex from thermo-sensitive poly( $N$-isopropylacrylamide $)$ hydrogels, International Journal of Pharmaceutics, 402 (1), 123-128 (2010).

87. S.K. Bajpai and S. Saxena, Enzymatically degradable and $\mathrm{pH}$-sensitive for colon-targeted oral drug delivery. I. Synthesis and characterization, Journal of Applied Polymer Science, 92 (6), 3630-3643 (2004).

88. D. Myung, D. Waters, M. Wiseman, P.E. Duhamel and J. Noolandi, Progress in the development of interpenetrating polymer network hydrogels, Polymers for Advanced Technologies, 19 (6), 647 657 (2008)

89. Y.Y. Liu, Y.H. Shao and J.Lu, Preparation, properties and controlled release behaviors of $\mathrm{pH}-$ induced thermosensitive amphiphilic gels, Biomaterial, 27 (21), 4016-4024 (2006).

90. K.P.F. Thomas, Degradable cross-linking agents as cross-linked network polymers formed therewith, US 2003/007839, 2003.

91. A. Mittur, Temperature modulation of transdermal drug delivery, US 2006/0135911, 2009.

92. Z. Kresa, J. Rems and O. Wichterle, Arch Otholaryngol, 17, 360-365 (1973).

93. L. Šprincl, J. Vacìk, J. Kopeček and D. Lìm, Biological tolerance of poly $(N$-substituted methacrylamides), Journal of Biomedical Materials Research, 5 (3), 197-205 (1971).

94. J. Kopeček, L. Šprincl, H. Bažilová and J. Vacìk, Biological tolerance of poly( $N$-substituted acrylamides), Journal of Biomedical Materials Research, 7 (1), 111-121 (1973).

95. L. Šprincl, J. Vacik and J. Kopeček, Biological tolerance of ionogenic hydrophilic gels, Journal of Biomedical Materials Research, 7 (1), 123-136 (1973). 
96. L. Šprincl, J. Kopeček and D. Lìm, Effect of the structure of poly(glycol monomethacrylate) gel on the calcification of implants, Calcified tissue Research, 13 (1), 63-72 (1973).

97. J. Kopeček and L. Šprincl, Relationship between the structure and biocompatibility of hydrophilic gels, Polimery w medycynie, 4 (2), 109 (1974).

98. Z. Voldřich, Z. Tománek, J. Vacìk and J. Kopeček, Long-term experience with poly(glycol monomethacrylate) gel in plastic operations of the nose, Journal of Biomedical Materials Research, 9 (6), 675-685 (1975).

99. A. Kř́stek, B. König and O. Wichterle, Beitrag zur chirurgischen Therapie der Netzhautablösnung. Die Erfahrungen mite der Verwendung von Polyglykolmethacrylat als Material für Plomben bei der Custodis-Operation), Klin Monatsbl Augenheilkd, 149, 219-227 (1966).

100. O. Wichterle, Method of manufacturing soft and flexible contact lenses, US 3496254, 1964.

101. O. Wichterle, Method of production of lenses with aspherical surfaces, US 3497577, 1966.

102. R. Spohr, M. Tamada, H. Omichi, Ch. Trautmann, J. Vetter and M. Yoshida, Chemical valve, EP 562303, 1993.

103. O. Wichterle, K. Kliment, J. Vacik, Z. Ott, M. Stol and J. Dvorak, Hydrogel substitutes for tubular somatic organs, US 3862452, 1971.

104. J.F. McBride, S.H. Gehrke and J.P. Fisher, Temperature-controlled solute delivery system comprising cellulose ethers, WO 99/49908, 1999.

105. E.C. Peters, F. Svec and J. Frechet, Thermally responsive polymer monoliths, US 5929214, 1999.

106. O. Wichterle, Method and apparatus for introducing fluids into the body, US 3971376, 1976.

107. J.F. McBride, S.H. Gehrke and J.P. Fisher, Temperature controlled solute delivery systems, US 6733788, 2004.

108. Y. Murayama, F. Vinuela and Y. Mori, Thermo-reversible polymer for intralumenal implant, WO 2000/045868, 2000.

109. R.E. Weller, M.A. Lind, D.R. Fisher, A. Gutowska and A.A. Campbell, Polymer-based stimulussensitive gels as radioisotope carriers, WO 99/55386, 1999.

110. Y. Li, Z. Hu and X. Zhang, Synthesis and use of heterogeneous polymer gels for environmentally controlled change, US 5976648, 1999.

111. H. Jiang, S. Kelch and A. Lendlein, Polymers move in response to light, Advanced Materials, 18 (11), 1471-1475 (2006)

112. A. Lendlein, H. Jiang, O. Junger and R. Langer, Lightinduced shape-memory polymers, Nature, 434 (7035), 879-882 (2005).

\section{HIDROGELOVI OSETLJIVI NA SPOLJNE STIMULANSE ZA FARMACEUTSKU I MEDICINSKU PRIMENU}

\section{Snežana Ilić-Stojanović, Ljubiša Nikolić, Vesna Nikolić, Slobodan Petrović, Mihajlo Stanković, Ivana Mladenović-Ranisavljević}

Hidrogelovi su umreženi trodimenzionalni hidrofilni polimeri koji bubre u vodi $i$ vodenim rastvorima, a sami se ne rastvaraju u njima. Jako su osetljivi na spoljne stimulanse, što se manifestuje oštrim faznim prelazom. Ova osobina je važna za njihovu primenu u oblasti farmacije, i to pre svega za izradu formulacija sa kontrolisanim oslobađanjem aktivnih principa, uz korigovanje rastvorljivosti, degradacije i smanjenja njihove toksičnosti. Zahvaljujući kompatibilnosti sa živim tkivima, primena hidrogelova je važna i za rešavanje različitih medicinskih potreba (za izradu kontaktnih sočiva, stentova, balon katetera, veštačkih mišića, zamena za arterije i vene, traheja, jajovoda). U radu su detaljno prikazane metode za njihovo dobijanje (hemijske i fizičke), svojstva i osetljivost na spoljne stimulanse (temperatura, pH, magnetno polje), kao i moguće primene u oblasti medicine i farmacije.

Ključne reči: hidrogelovi, inteligentni gelovi, sistemi oslobađanja lekova, umrežavanje, $N$-izopropilakrilamid 